\title{
A Novel Method for nZEB Internal Coverings Design Based on Neural Networks
}

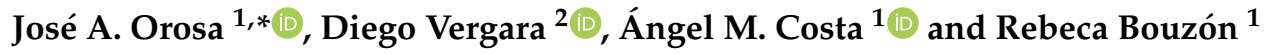 \\ 1 Department of Energy, Universidade da Coruña, Paseo de Ronda, 51, 15011 A Coruña, Spain; \\ angel.costa@udc.es (Á.M.C.); rebeca.bouzon@udc.es (R.B.) \\ 2 Department of Mechanical Engineering, Catholic University of Ávila, C/Canteros, s/n, 05005 Avila, Spain; \\ diego.vergara@ucavila.es or dvergara@usal.es \\ * Correspondence: jarosa@udc.es or jose.antonio.orosa@udc.es; Tel.: +34-981-167-000 (ext. 4320)
}

Received: 4 April 2019; Accepted: 25 April 2019; Published: 27 April 2019

check for updates

\begin{abstract}
Research from the International Energy Agency about indoor ambiences and nearly zero energy buildings (nZEB) in the past has been centred on different aspects such as the prediction of indoor conditions as a function of the weather using laboratory material properties for simulations and real sampled data for validation. Thus, it is possible to use real data for defining behavioural groups of indoor ambiences as a function of real vapour permeability of internal coverings. However, this method is not suitable for modelling it and predicting its behaviour under weather changes, which is of interest to improve the method of selection and use of building construction materials. In this research, artificial intelligence procedures were employed as the first model of permeable coverings material behaviour to provide a newer understanding of building materials and applications for the generation of new control procedures between the mechanical and electronic point of view of building construction materials.
\end{abstract}

Keywords: ANNs; passive methods; building energy; internal covering

\section{Introduction}

In the last decade, several research papers have attempted to evaluate and model the effect of building materials overheat and mass transfer processes [1,2]. Taking into account that the construction of nearly zero energy buildings (nZEB) requires innovative design processes based on an integrated design approach facilitated by multidisciplinary work teams [3], different research groups under the organisation of the International Energy Agency (IEA) shared real sampled laboratory data [4], new software resources like HAM tools [5] and real in-situ sampled data to validate the previous ones [6]. Thus, the aim of the present research was to validate software resources based on real sampled data to simulate and potentially predict and improve indoor conditions in buildings by using buildings construction materials as mechanical control systems in the future.

Accurate prediction of temperature and relative humidity in indoor ambiences is difficult to obtain unless a realistic understanding of the existing buildings is available. In this sense, the real properties of building materials once placed in the structure and its effect on indoor conditions as a consequence of its real behaviour must be analysed in detail for future optimisation.

The effect of internal coverings on indoor ambiences was reflected by statistical analysis in previous research works [6-11]. Specifically, in previous studies carried out by the same research group of the present paper [6-10], authors sampled indoor conditions of 25 office buildings in a year in a humid region of the Northwest Spain. The main results revealed how internal coverings exert a clear effect on indoor ambiences during non-occupancy period due to low air changes during the longer period at night. Furthermore, analysis of variance (ANOVA) revealed more interesting results that an 
average indoor relative humidity controlled by these passive methods reaches a more comfortable ambience with a lower need of energy for conditioning during the first hour of occupation $[8,9]$.

As a consequence of these results, internal coverings were considered to be of special interest to act as permeable or impermeable barrier materials for use as building construction materials in order to control thermal comfort, energy saving and, in general, indoor conditions. The real sampled data demonstrated how this effect must be considered, although it was nearly depreciated during years in most of heat and mass transfer software resources—like, for instance, EnergyPlus—due to the difficulty understanding and define this process. Furthermore, the main results founded in previous papers of our research group [6-10] emphasize the importance of simulating and modelling real sampled data rather than just employing laboratory results as a consequence of the modifications that are experimented by these materials until its final placement.

On the other hand, artificial neuronal networks (ANNs) were described recently as the last step in data mining [12-16]. In particular, most times, statistical studies do not let us get a model of real processes despite the fact its main variables were previously statistically related. ANNs are the clearest solution to model and predict these non-linear processes with promising future applications.

In previous works [6-10], different indoor ambiences of 25 office buildings were classified based on both its internal coverings materials and the statistical studies of real sampled data of its indoor ambiences. In the present study, this hygroscopic behaviour of coverings materials will be modelled in a more exactly way by Multi-output Gaussian Process Regression Artificial Neural Networks (MGPR ANNs) once trained and tested with the aim to be employed in future indoor ambience predictions. Moreover, this more accurate model will help to improve office buildings envelope redesign [17] to control the heat and mass transfer process between indoor air and wall construction materials and, in consequence, it will serve as a guide to improve the existing indoor conditions [18-22].

\section{Materials and Methods}

\subsection{Office Buildings}

The present research is the second phase of a previous work in which solution to the prediction problem of indoors conditions based on real properties of building construction materials were discussed [6,7]. The office buildings used in this study were located in the city of A Coruna, which is identified as an extremely humid region in the Northwestern Spain. Their building construction characteristics, like in previous works, can be defined as identical as these buildings were constructed at the same time and with the same design criteria.

All these offices were destined to be bank offices placed in the ground floor of each respective building. In all these offices two main zones can be identified (Figure 1a): (i) clients' zone and (ii) employees' zone. In the employees' zone there are three employees during all the working period that goes from 8:00 till 14:00. Most of the day, the workers use to enter few minutes before to prepare for the morning's work, and from 16:00 till 19:00. Therefore, the unoccupied period was considered to be 19:00-09:00 h. On the other hand, an average value of three clients is estimated in the clients' zone during the working hours waiting to be attended. In this sense, this working period can be identified as a humidity generation period of time of $7 \mathrm{~h}$.

It must be emphasised that these offices did not have any kind of air conditioning systems, except for mechanical ventilation which was rarely employed during the day under extreme occupation conditions and, more importantly, there were a high number of infiltrations due to the natural ventilation through the doors when they were open as a consequence of the transit of clients. In consequence, during this occupation period, the air changes in the office were high and humidity is released to outdoors. Once the office closes, the air changes are reduced, and the effect of wall constructions materials starts to work by controlling indoor ambience relative humidity based on the permeability level of the internal covering material employed in each office until the office will open again in the next morning. 


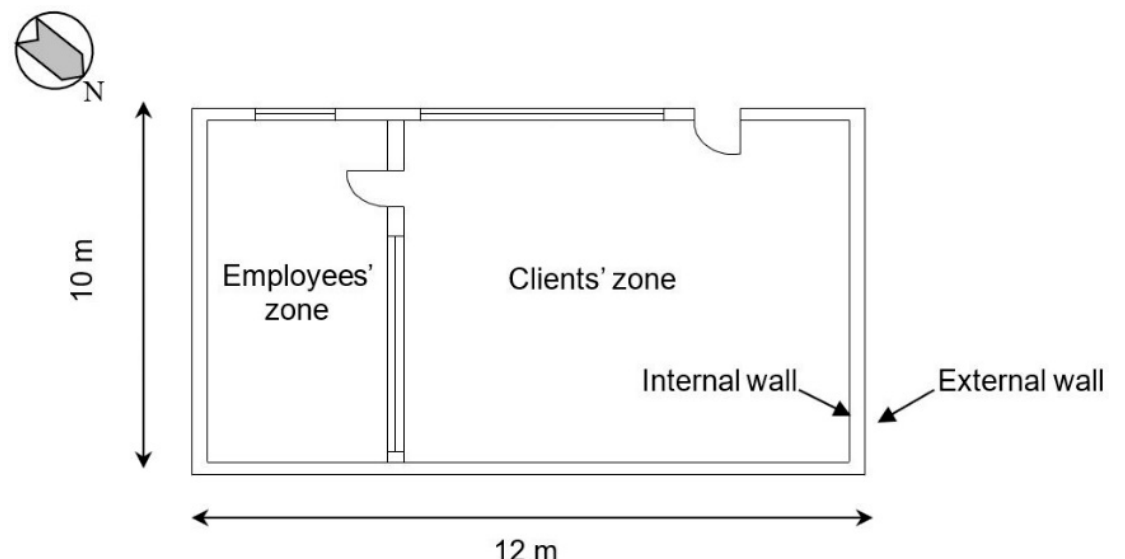

(a)

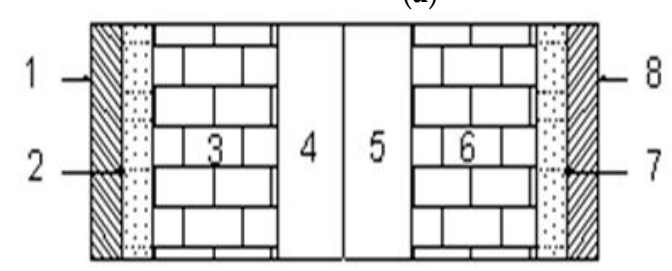

$\begin{array}{ll}\text { 1. External coating (marble) } & \text { 4. Air barrier }(3 \mathrm{~cm}) \\ K_{1}=2.6(\mathrm{~W} / \mathrm{m} \mathrm{K}) & K_{4}=0.024(\mathrm{~W} / \mathrm{m} \mathrm{K}) \\ \text { 2. Concrete }(1 \mathrm{~cm}) & \text { 5. Polystyrene }(3 \mathrm{~cm}) \\ K_{2}=0.42(\mathrm{~W} / \mathrm{m} \mathrm{K}) & K_{5}=0.03(\mathrm{~W} / \mathrm{m} \mathrm{K}) \\ \text { 3. Brick }(8 \mathrm{~cm}) & \text { 6. Brick }(8 \mathrm{~cm}) \\ K_{3}=0.69(\mathrm{~W} / \mathrm{m} \mathrm{K}) & K_{6}=0.69(\mathrm{~W} / \mathrm{m} \mathrm{K})\end{array}$

7. Concrete $(1 \mathrm{~cm})$

$K_{7}=0.42(\mathrm{~W} / \mathrm{m} \mathrm{K})$

8. Internal coating (plaster, $1 \mathrm{~cm}$ )

$K_{8}=0.17(\mathrm{~W} / \mathrm{m} \mathrm{K})$

$K_{6}=0.69(\mathrm{~W} / \mathrm{m} \mathrm{K})$

(b)

Figure 1. Walls' distribution: (a) office buildings zones; (b) detail of layers' distribution in a standard wall and their thermal conductivities $(K)$.

In particular, a typical wall structure can be defined as being composed of an external covering, concrete, brick, air barrier, polystyrene, brick, concrete, and internal covering, as it is shown in the walls' distribution in Figure 1. The only difference in the buildings was in the type of internal coverings used, as those ranged from paper, wood, paint and plastics, all of which differed in their water vapour permeability $\left(k_{\mathrm{d}}\right)$ levels. In this sense, the levels of water vapour permeability in real buildings were not defined in that works in a quantitative way due to One Way ANOVA just let us define the similarity in indoor ambiences behaviours for a significance level of 0.05 . As a consequence of this simple modification, different indoor temperature and relative humidity were identified with important effects on the thermal comfort and energy consumption. In particular, this effect was really intense during the first hours of occupation of the office buildings.

In previous studies [6-10], the external covering was of marble, while the internal coverings were of plastic, paint, wood, or paper, which were accordingly classified based on the real permeability levels $(1 / 200,1 / 100,1 / 45$, and $1 / 30 \mathrm{~g} \cdot \mathrm{m} / \mathrm{MN} \cdot \mathrm{s}$, respectively) obtained in laboratory test. In our case study, these same office buildings were employed with the same external covering of marble. This marble surface can be considered as do not act in moisture transfer through the wall due to its polished surface.

\subsection{Sampled Variables and Mathematical Models}

In the present case study, based on previous research works on heat and mass transfer processes of wall construction materials [6-10], the evolution with time of the indoor and outdoor partial vapour pressure was selected as the study variable. As explained earlier, indoor conditions of temperature and relative humidity were sampled with Tinytag Plus 2 dual channel dataloggers with thermistor 
and capacitive sensors were also installed to record temperature and relative humidity values with accuracies $+/-0.2{ }^{\circ} \mathrm{C}$ and $+/-3 \%$ of relative humidity, respectively [23].

These data loggers were placed in both employees' zone and clients' zone section of the office building with a sampling frequency of ten minutes for a period of one year. At the same time, based on weather information from nearer weather stations, it was possible to define the simultaneous indoor and outdoor conditions of temperature, relative humidity and pressure in each office building. Based on these moist air variables, it was possible to determine the partial vapour pressure inside and outside the office building.

Likewise, it must be remembered that moisture cumulated in building construction materials is released or adsorbed in only the first $4 \mathrm{~h}$, as it was determined by Hameury and Lundstrom based on real sampled data of indoor ambiences [24]. Therefore, the unoccupied period can be considered a long period of time where, as revealed in previous research [6-9], the moisture transfer equation depended on the partial vapour pressure. Based on this, it was possible to define a clear relation between partial vapour pressure and moisture transfer equation during the night time, as detailed in Equation (1).

$$
q_{\mathrm{M}}=-k_{\mathrm{d}}(u, T) \nabla P_{\mathrm{v}}-\rho_{\mathrm{o}} D_{\mathrm{w}}(u, T) \nabla u+v_{\text {air }} \rho_{\mathrm{v}}+K \rho_{\mathrm{w}} g
$$

where $q_{\mathrm{M}}$ is the mass flux $\left(\mathrm{kg} /\left(\mathrm{m}^{2} \cdot \mathrm{s}\right)\right), k_{\mathrm{d}}$ is the vapour permeability $(\mathrm{kg} /(\mathrm{s} \cdot \mathrm{m} \cdot \mathrm{Pa})), u$ is the moisture content $\left(\mathrm{kg}_{\text {water }} / \mathrm{kg}_{\text {Dry air }}\right), P_{\mathrm{v}}$ is the partial pressure of water vapour $(\mathrm{Pa}), \rho_{0}$ is the dry density of porous material $\left(\mathrm{kg} / \mathrm{m}^{3}\right)$, and $D_{\mathrm{w}}$ is the liquid moisture diffusivity $\left(\mathrm{m}^{2} / \mathrm{s}\right)$.

Thus, it was possible to assume that, for long periods of time, despite the fact that during the first $4 \mathrm{~h}$ of the unoccupied period the air changes were reduced and materials actuated realising or adsorbing humidity, the partial vapour pressure depends on the first term of the Fick's law, as shown in Equation (1).

After the main data was obtained, it was possible to train an ANN with various input variables and only one output variable for future optimization. Thus, it was possible to train the network with the outdoor temperature and relative humidity as well as define indoor vapour pressure values.

\subsection{Neural Nets Predictions and Software Resources}

An artificial neural network (ANN) or neural network toolbox (NNT) receives numeric inputs, performs different computation processes with them and provides an output. To reach this objective, a neural network takes to connect units defined as nodes (neurons) arranged in layers. The first layer receives the input data and transmits this to the next hidden layers until reaching the final output value.

Based on these principles, an NNT is employed as an alternative to traditional statistical procedures and it is usually employed as a function of approximation to define complex relationships under great reliability when the output value is a single variable. Since in previous works [6-9] it was possible the aggrupation of 25 office buildings based on a statistical similarity of its indoor moist air evolution as a function of weather conditions or, what is the same, 25 office buildings with the same internal covering permeability level (permeable, semi-permeable and impermeable internal covering material), now it should be possible to find the same results by means NNT. What is more, if now we train some indoor ambiences of one representative office building of each internal covering permeability level as a function of weather conditions by means of NNT, it would be a really interesting tool for redesign indoor ambiences in future office buildings.

Different considerations during the NNT configuration were done to reach this objective:

- Selection of NNT: There are different types of nets such as Multi-Layer Feedforward Network (MLF), Generalized Regression Neural Nets (GRN) and Probabilistic Neural Nets (PN). In an MLF net, the user must define the topology (number of layers and nodes), while, in a GRN/PN net, there is no need to make topology decisions and two hidden layers are employed. It must be remembered that the net topology is the selection of the number of layers and the number of nodes in the layer that determines the network capacity to learn the relationship between independent 
and dependent variables. At the same time, the main literature conclusions [25-28] about network topology are that a single hidden layer with few nodes is sufficient for most cases. Considering that this was the first of its kind study, a probabilistic neural network (GRN/PN) was selected to reach a precision level during the training and testing processes, as shown in Figure 2.

- Control algorithm: it is important to highlight that the error, which is measured as the mean square difference between the actual output value and the output value obtained from the net while training the numerical prediction, is employed as the control parameter to stop the training process.

- Prevention of over-training: NNT needs to prevent over-training. Over-training is when the net not only learns the general relations between variables and is very near to the particular case employed during the training. In this sense, as a normal validation procedure a part of the training data-usually $20 \%$ of the sampled data-is employed to test the net once it is trained.

- Input variables: the minimum number of input values to train a network was considered. As the sampling process of temperature and relative humidity during the unoccupied period of the offices was about $10 \mathrm{~min}$, the number of values obtained for each variable during few other nights can be considered sufficient to train and test a neural net.

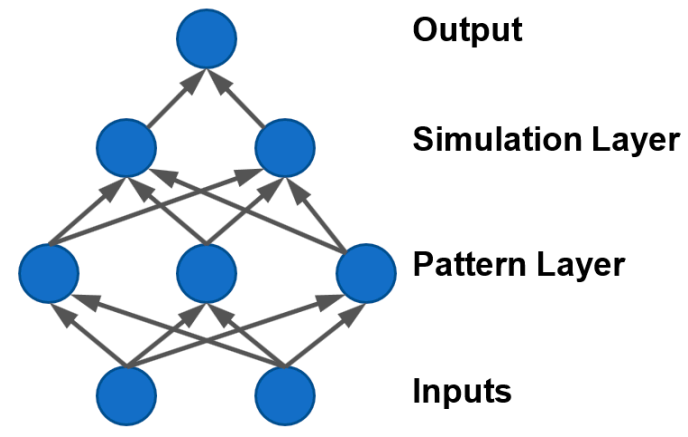

Figure 2. Example of Generalized Regression Neural Nets (GRN) net.

Finally, once main considerations for our training procedure were done, Matlab Simulink Neural Network Toolbox (R2015b) [29] was selected as software resource to develop this task due to its so specific toolbox and configuration for this so simple initial case study.

\section{Results}

\subsection{ANN Selection and Training}

As explained earlier, 25 neural networks were trained and tested based on indoor and outdoor sampled data during the extreme winter and summer seasons to develop future predictions of indoor ambiences as a function of the daily weather. In particular, a GRN/PN network was selected as a dependent variable of the indoor partial vapour pressure and an independent variable for the outdoor partial vapour pressure.

As the frequency of 10 min gave about 80 samples per day during the unoccupied period, more than 1 week was needed to obtain a minimum training data of 300 samples. Finally, $75 \%$ of the data were employed to train the network and $25 \%$ were employed to validate the same.

The stopping criteria were the minimum absolute number of errors obtained in most of the indoor vapour pressure predictions. In particular, the maximum absolute error allowed was fixed in 6 during the training and 9 during the testing (standard deviation $\pm 8 \%$ ), which represents an actual nearly null percentage of incorrect predictions [25-28] as a clear example of the power of ANNs to model this process. Finally, all this training process required about $1 \mathrm{~h}$ per office building, in a Hewlett Packard Intel i5-4200U computer. 


\subsection{Validation Results}

Like in past studies [6-10], extreme office buildings were analysed because their behaviour can be identified easily as a consequence of the real permeability level. As a consequence, indoor ambiences in these different offices were trained in the previous section and now simulated by the obtained ANNs models to be tested. Results showed a good agreement between the sampled and predicted curves of indoor partial vapour pressure as a function of outdoor weather conditions (outdoor partial vapour pressure), as reflected in Figures 3-6.

In such figures, more than 700 values of the outdoor weather conditions are employed to test the NNT and represented by a red line, its respective sampled indoor conditions by a blue line, and the predicted values obtained by the NNT are shown in a green line. On the horizontal axis, part of the number of samples of indoor and outdoor conditions with a time frequency of ten minutes are shown.

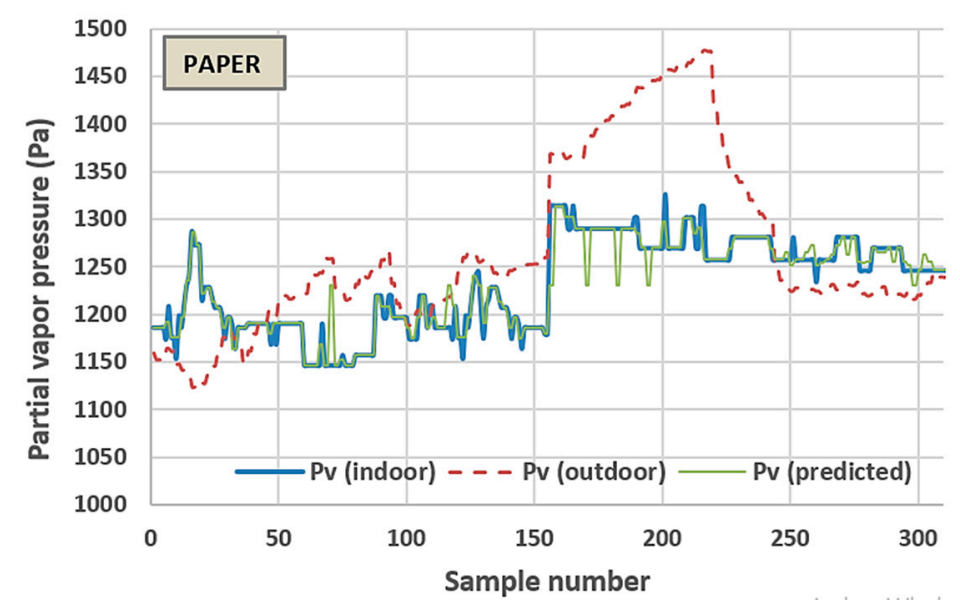

Figure 3. Partial vapour in office buildings using paper as an internal covering material.

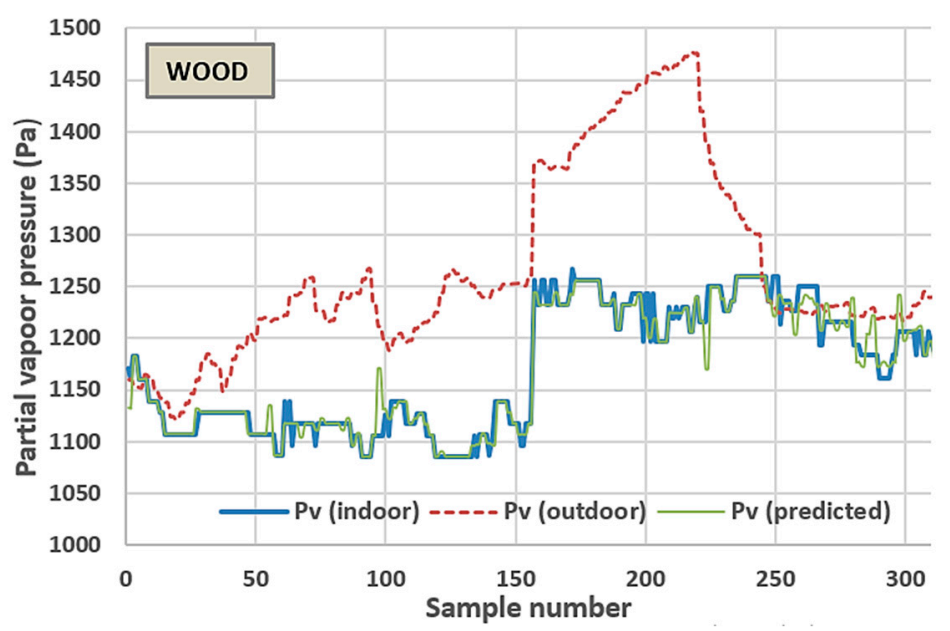

Figure 4. Partial vapour in office buildings with wood as an internal covering material. 


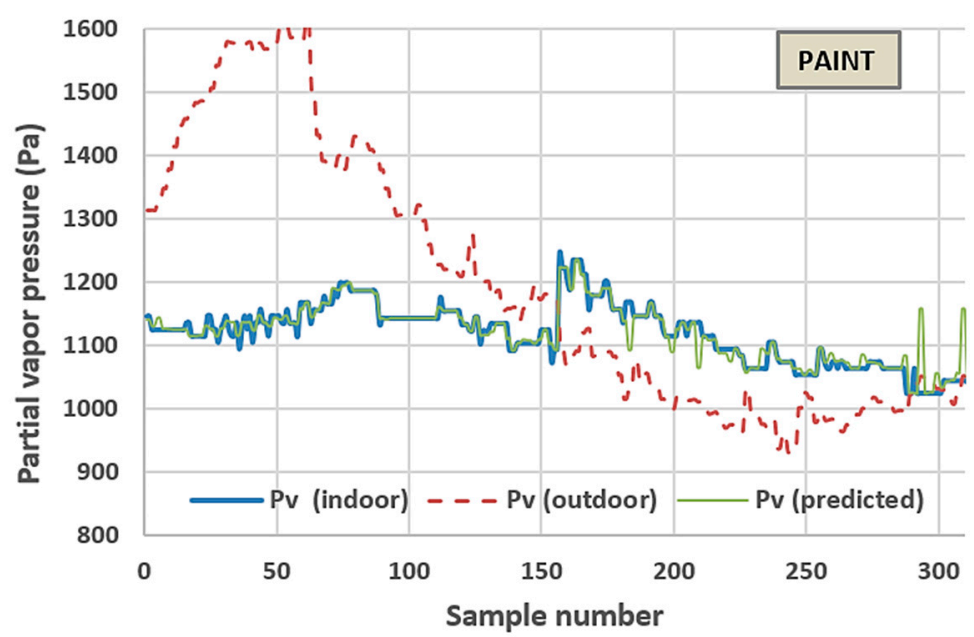

Figure 5. Partial vapour in office buildings with paint as an internal covering material.

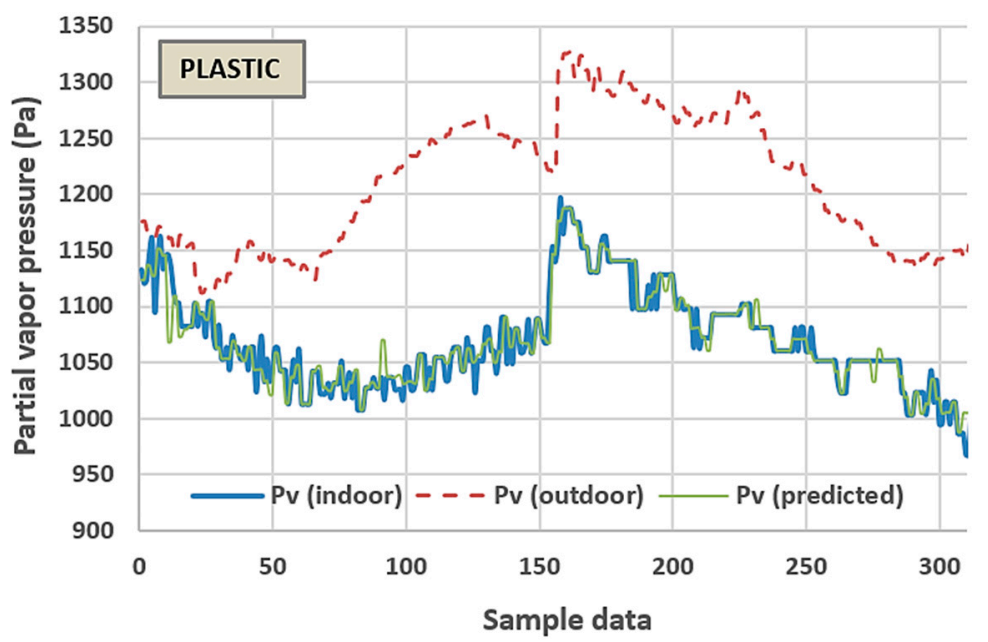

Figure 6. Partial vapour in office buildings with plastic as an internal covering material.

\subsection{Internal Coverings Behaviour Characterisation}

Once a neural net is trained for each of the interesting office buildings in accordance with a previous study -in which a testing laboratory bedroom was the subject of simulated outdoor weather conditions to analyse indoor ambience behaviour [4], in the present case study, partial vapour pressure was changed from 1200 to $1400 \mathrm{~Pa}$ and to $1000 \mathrm{~Pa}$ as outdoor weather conditions, and the predicted indoor conditions were compared with the effects obtained in the testing chamber. This procedure will allow one to understand the real behaviour of internal coverings in a transient process as it happens in real buildings and not in testing chambers.

Once each of the office building was modelled and tested with a neural network, past results obtained in [6-10] were applied to analyse the predicted values of internal vapour pressure for each office as a function of its internal covering effect. So, in Figures 7 and 8 it can be observed how the same sampled per hour weather conditions were employed as input data for each one neural network after trained. Because of this, a new output value for each different internal covering is represented in the unoccupied period (Figure 7) and occupied period (Figure 8). In this way, it can be observed in such figures the predicted effect over indoor ambiences partial vapour pressure of each internal covering under the same outdoor weather conditions. 


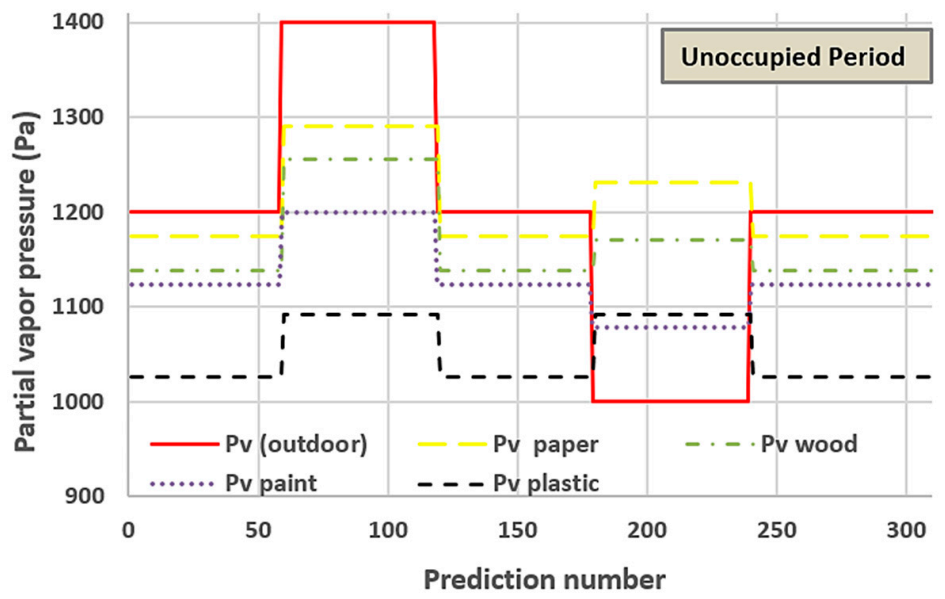

Figure 7. Artificial neural networks (ANNs) prediction of indoor and outdoor partial vapour pressure during the unoccupied period.

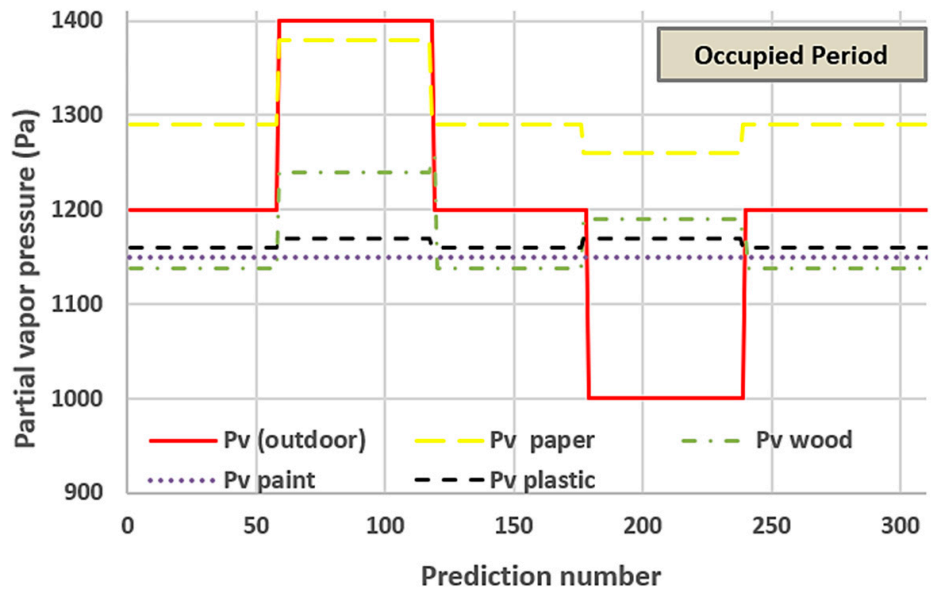

Figure 8. ANNs prediction of indoor and outdoor partial vapour pressure during the occupied period.

\section{Discussion}

In the past, the authors found that permeable covering tended to control indoor partial vapour pressure during the unoccupied period as a consequence of low air changes [6-10]. In this regard, permeable covering materials such as paper and wood reach a lower maximum humidity in the summer and a higher minimum humidity in the winter than impermeable ones [6]. As a consequence, permeable coverings are considered as very resourceful internal covering material for seeking thermal comfort and, at the same time, for improving the energy saving $[8,9]$.

From these works it was concluded that, as a consequence of long periods of inoccupation-which can be considered to be longer than $4 \mathrm{~h}$, permeable internal coverings can serve to control indoor ambiences to comfortable levels, thereby resulting in lower energy consumption for air conditioning the indoor ambiences during the first hour of occupation.

As explained earlier (Figures 3-6), NNT can be trained to predict indoor partial vapour pressure as a function of outdoor weather conditions. From these trained networks, the effect of permeable internal coverings can be analysed during the winter season for different experimental values of the outdoor weather conditions.

Furthermore, as the networks were trained for unoccupied and occupied periods, the respective effects could be analysed separately (Figures 7 and 8, respectively). Figure 7 depicts examples of outdoor winter weather conditions for this region (Galicia, a humid region of the Northwest Spain), which presents lower partial vapour pressure than that in summers. In this figure, the red line indicates a partial pressure evolution from 1200 to $1400 \mathrm{~Pa}$ and from 1200 to $1000 \mathrm{~Pa}$. As a consequence of this 
evolution, during the unoccupied period, permeable materials like paper (represented by a yellow line) allow indoor partial vapour pressure to reach the higher value of nearly $1300 \mathrm{~Pa}$ and, when this outdoor value is reduced to $1000 \mathrm{~Pa}$, the permeable coverings tended to release the cumulated moisture to indoor ambience and increase the partial vapour pressure till $1225 \mathrm{~Pa}$, which is in clear agreement with the main results obtained in previous research works [6-10].

At the same time, in accordance with its permeability level, the remaining internal coverings act in a similar or less intense manner. For wooden materials (represented in green line), a similar behaviour as of paper was seen, albeit with a lower peak of indoor partial vapour values.

On the other hand, more impermeable materials such as paint demonstrated no sensitivity to the outdoor weather conditions and maintained its initial value during all experiments. An example of the behaviour of relay impermeable materials by impermeable materials like plastic is represented by a black dashed line (see Figure 7). As can be seen, when the outdoor weather condition changes, these materials exert lower partial vapour pressure on the indoor ambiences. This effect is in contraposition with the comfort conditions and the related energy consumption to condition this ambience; which is in in clear agreement with previous papers [6-10].

If the effect of these same outdoor weather conditions is analysed during the occupation period when the air changes are much higher, the effect of internal covering cannot be clearly detected and may be neglected (see Figure 8). From this figure, it can be can conclude that most of the offices tended to maintain their partial vapour pressure to an average value of $1100 \mathrm{~Pa}$, and, only permeable materials showed an average value during this occupation period. In particular, indoor ambiences of offices with paper (yellow) or wooden (green) internal coverings showed an evolution influenced by outdoor weather conditions. This result is in agreement with previous research works [6-10].

According to the need of the technicians to understand the proposed procedure to relate indoor and outdoor conditions and internal coverings properties and, in particular, with the aim to define an adequate mathematical model that could be employed for engineers and architects, different simulations were needed to obtain this relation to our particular buildings, like in previous studies [30,31]. In this sense, NNT results revealed that it was possible to define an adequate three-dimensional model obtained, like in previous research works [31], by curve fitting of data previously obtained from software resources like Energy Plus or by neuronal networks for different internal covering materials (see Figures 9 and 10). This behaviour was simulated under an outdoor partial vapor pressure of 800-1200 Pa to show the expected indoor partial vapor pressure.

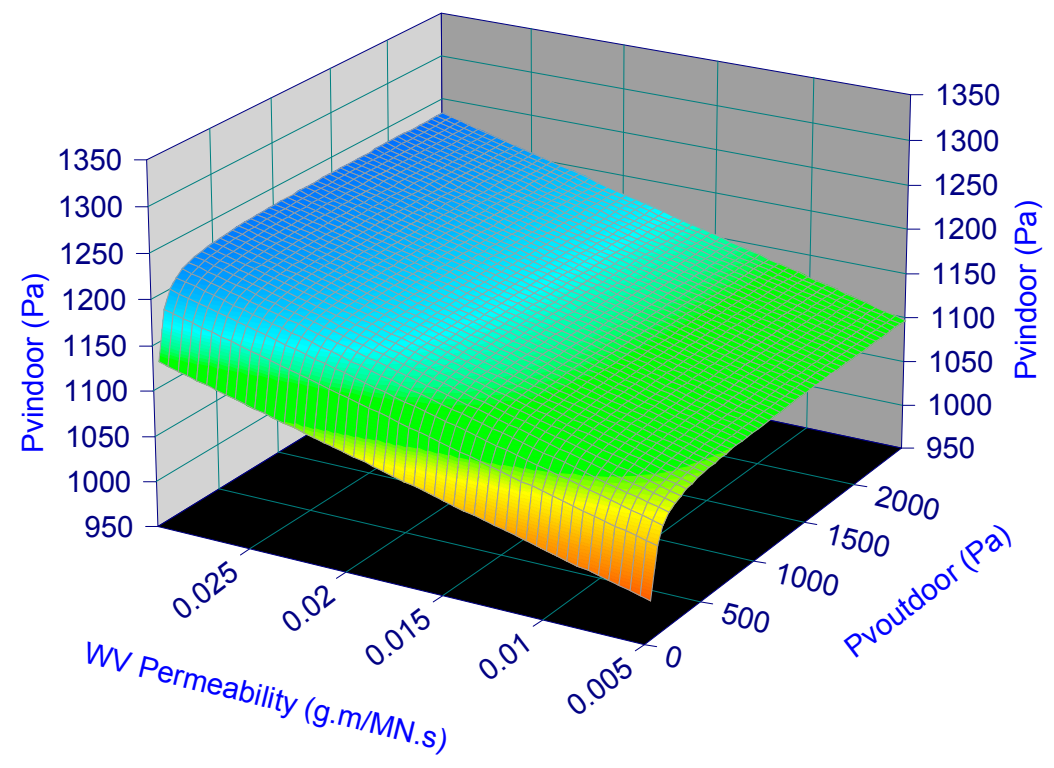

Figure 9. Indoor vapour pressure as a function of outdoor conditions and permeability during the unoccupied period. 


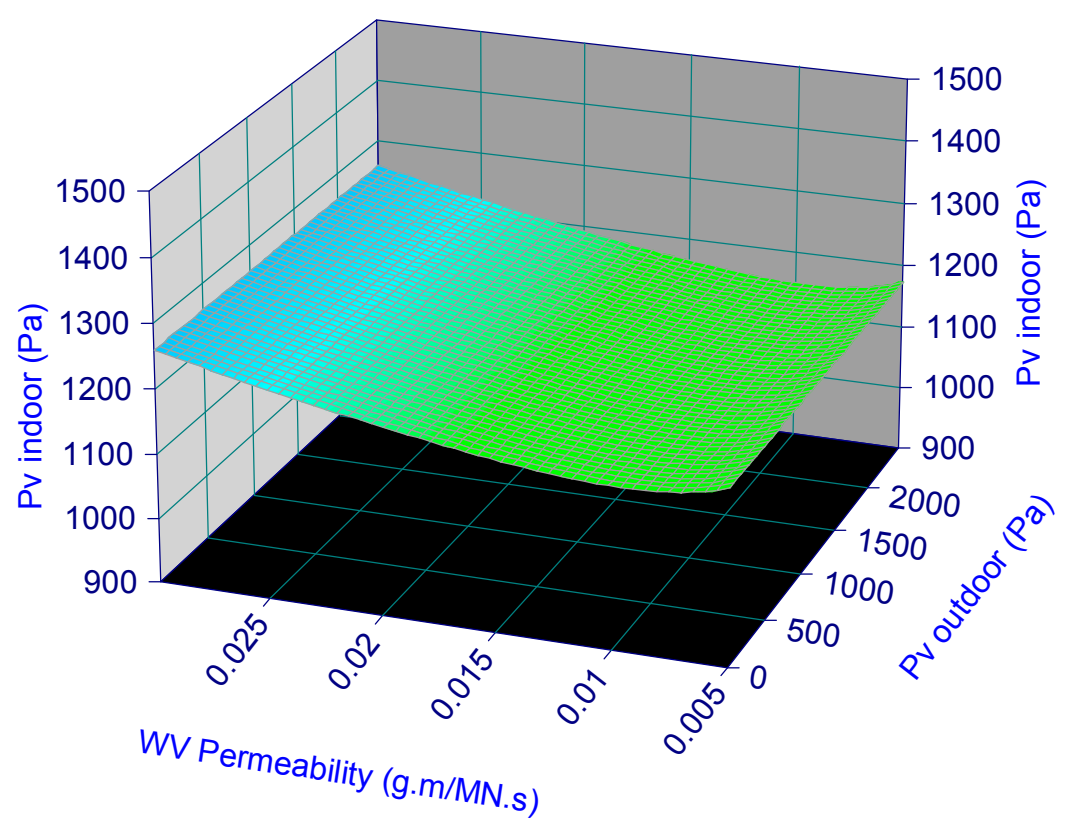

Figure 10. Indoor vapour pressure as a function of outdoor conditions and permeability during the occupied period.

Owing to both the need for an initial permeability value for each internal covering material to develop a final model that considers this variable and the values reflected in previous research works from test laboratories about the permeability level of the same materials [6-10], previously defined values were employed as the second input variable for the curve-fitting process. In this case, the determination factor was $r^{2}=0.806$ and the model obtained was reflected in Equation (2).

$$
P_{\mathrm{v} \_ \text {indoor }}=1072.1-\frac{5494.6}{P_{\mathrm{v} \_ \text {outdoor }}}+5460.7 \times k_{\mathrm{d}}
$$

where $P_{\mathrm{v}_{\_} \text {indoor }}$ is the indoor water vapor pressure $(\mathrm{Pa}), P_{\mathrm{v}_{-} \text {outdoor }}$ is the outdoor water vapor pressure $(\mathrm{Pa})$ and $k_{\mathrm{d}}$ is the internal coverings water vapor permeability $(\mathrm{g} \cdot \mathrm{m} / \mathrm{MN} \cdot \mathrm{s})$.

It is interesting to highlight that, if the obtained Equation (2) is employed in an inverse way, it is possible to define the real permeability value in these real buildings through the sampled indoor and outdoor partial vapor pressure. Therefore, it could be a new and original methodology to determine the real effect of internal coverings and to determine how it was changing through the time due to materials' waste and damage.

Considering that this process occurs during long periods of time and in accordance with the moisture transfer equation (Equation (2)), only the first term must be modelled in this process as a consequence of the study period is concluded. In this sense, the second term of Equation (2) shows the effect of cumulated moisture in internal coverings. This effect will control indoor ambiences during a maximum of $4 \mathrm{~h}$, after which its control capability remains only a function of the water vapour permeability, the first term of Equation (2).

On the other hand, the three-dimensional model of the occupied period revealed a horizontal plane that shows an indoor ambience experimenting a nearly null influence of the permeability level of internal coverings as a consequence of a great number of air changes during the working hours. This result is in clear agreement with that in previous works [6-10], and, as a result, it cannot be defined a clear difference between material behaviours when the number of air changes in an indoor ambience is high. In conclusion, indoor ambience is a function of outdoor weather conditions.

Our results suggest that neuronal networks allow the definition of an accurate model that can be employed in prediction studies unlike traditional statistical studies. In this sense, a map of the relationship between indoor and outdoor partial vapor pressure was obtained. Furthermore, this chart 
depicts an example of a new methodology to define hygroscopic material properties after they are placed in their final construction position, which can be considered as the first step toward future indoor ambience simulation and optimization.

Finally, this method, based on sampled data and a new generation of data mining techniques is just an example of application to improve indoor ambiences towards thermal comfort improvement and energy saving optimization. Furthermore, future applications of this procedure will help to improve indoor ambiances based on the amount and type of internal covering employed in an indoor ambience towards a natural control system of indoor ambience based on this building constants and passive methods.

Future works of this effect during the summer must be done to validate the effect of internal coverings materials, as it was concluded by previous researchers [32,33], and try to model this. Furthermore, final works about the effect of local thermal comfort and the energy peak during the first hours of occupation must be done and, furthermore, about the optimization of passive and active strategies in the early phase of a building's life cycle [30].

More other points of view can be considered at the time of selecting internal coverings, e.g., the prevention of fire expansion in office buildings. Anyway, based on the obtained experience, impermeable coverings are usually employed because plastic and glass are easier to be cleaned than paper and wood, which turns out to be a decisive aspect in the selection of coatings for public buildings.

\section{Conclusions}

The present research proposes a new methodology to predict the indoor ambience based on NNT procedure and using real-sampled data that would provide better insights to future research toward improving the system of predicting indoor ambiences and reaching a more detailed database of real material properties.

From this research, it can be concluded that it is possible to develop a predictive model of internal coverings' effect based on ANN and real-sampled data. This way, such a model becomes a useful tool to help predict the expected materials thermal behaviour. Furthermore, obtained ANN models showed that the control level of internal coverings is directly related to the vapor permeability, which is in clear agreement with previous statistical studies, thereby indicating the validity of this methodology.

In this case study, a common indoor partial vapor pressure model was obtained as a function of the permeability level of internal coverings and outdoor weather conditions during non-occupancy. Our results suggest that, as a consequence of the long period of non-occupation, the average effect of moisture release of materials can be neglected, and the model can be identified as the first term of the moisture transfer equation.

Simultaneously, the second model that reflects the same indoor conditions during the occupancy period as a function of material permeability level and outdoor weather conditions can be represented by a nearly horizontal plane. In other words, during this period, as a consequence of the high number of air changes, the permeability effect of internal coverings does not exert any effect on the indoor conditions.

Furthermore, as an example of the predictive accuracy of the ANN, our results showed that, during the winter unoccupied period, permeable materials tended to increase the internal partial vapor pressure and, on the contrary, impermeable internal coverings demonstrated the opposite behaviour. These results are in clear agreement with the main results obtained in our earlier studies [6-10].

Finally, for future research, the authors plan to focus on developing systems to improve thermal comfort and optimize energy saving on an average and during peak conditions, especially during the first hours of occupation. Furthermore, in-detail analysis of a new internal coverings design criteria based on these results is warranted. 
Author Contributions: Conceptualization, J.A.O.; Methodology, J.A.O., Á.M.C. and R.B.; Software, J.A.O.; Validation, D.V., Á.M.C. and R.B.; Formal Analysis, J.A.O., D.V., Á.M.C. and R.B.; Data Curation, J.A.O. and D.V.; Writing-Original Draft Preparation, J.A.O.; Writing-Review and Editing, J.A.O. and D.V.

Funding: This research was funded by CYPE Ingenieros S.A. in their research project to reduce energy consumption in buildings and its certification, in collaboration with the University of A Coruña (Spain) and the University of Porto (Portugal) (Grant No. 64900).

Acknowledgments: The authors wish to express their deepest gratitude to the Sustainability Specialization Campus of the University of A Coruña for the administrative and technical support.

Conflicts of Interest: The authors declare no conflict of interest.

\section{References}

1. Padfield, T. The Role of Absorbent Building Materials In Moderating Changes of Relative Humidity. Ph.D. Thesis, The Technical University of Denmark, Kgs. Lyngby, Denmark, October 1998.

2. Hens, H. Indoor Climate in Student Rooms: Measured Values. IEA-EXCO Energy Conservation in Buildings and Community Systems Annex 41 “Moist-Eng” Glasgow Meeting. 2004. Available online: https://www. researchgate.net/publication/237716820_Indoor_climate_in_student_rooms_measured_values (accessed on 24 March 2019).

3. Cromwijk, J.; Mateo-Cecilia, C.; Jareño-Escudero, C.; Schröpfer, V.; Op't Veld, P. An introduction to a novel and rapid nZEB skill-mapping and qualification framework methodology. Buildings 2017, 7, 107. [CrossRef]

4. EBC Annex 41. Available online: http://www.iea-ebc.org/projects/project?AnnexID=41 (accessed on 27 April 2019).

5. Kalagasidis, A.S. Ham-Tools-An Integrated Simulation Tool for Heat Air and Moisture Transfer Analysis in Building Physics. Ph.D. Thesis, Chalmers University of Technology, Gothenburg, Sweden, January 2004.

6. Orosa, J.A.; Baaliña, A. Passive climate control in Spanish office buildings for long periods of time. Build. Environ. 2008, 43, 2005-2012. [CrossRef]

7. Orosa, J.A.; Baaliña, A. Improving PAQ and comfort conditions in Spanish office buildings with passive climate control. Build. Environ. 2009, 44, 502-508. [CrossRef]

8. Orosa, J.A.; Oliveira, A.C. Energy saving with passive climate control methods in Spanish office buildings. Energy Build. 2009, 41, 823-828. [CrossRef]

9. Orosa, J.A.; Oliveira, A.C. Reducing energy peak consumption with passive climate control methods. Energy Build. 2011, 43, 2282-2288. [CrossRef]

10. Orosa, J.A.; Oliveira, A.C.; Ramos, N.M.M. Experimental quantification of the operative time of a passive HVAC system using porous covering materials. J. Porous Media Palgrave Macmillan 2010, 13, $637-643$. [CrossRef]

11. Mazzeo, D.; Oliveti, G.; Arcuri, N. A method for thermal dimensioning and for energy behavior evaluation of a building envelope PCM layer by using the characteristic days. Energies 2017, 10, 659. [CrossRef]

12. Chou, J.S.; Bui, D.K. Modeling heating and cooling loads by artificial intelligence for energy-efficient building design. Energy Build. 2014, 82, 437-446. [CrossRef]

13. Buratti, C.; Lascaro, E.; Palladino, D.; Vergoni, M. Building behavior simulation by means of artificial neural network in summer conditions. Sustainability 2014, 6, 5339-5353. [CrossRef]

14. Tian, Q.; Zhao, W.; Wei, Y.; Pang, L. Thermal environment prediction for metro stations based on an RVFL neural network. Algorithms 2018, 11, 49. [CrossRef]

15. Xu, X.; Feng, G.; Chi, D.; Liu, M.; Dou, B. Optimization of performance parameter design and energy use prediction for nearly zero energy buildings. Energies 2018, 11, 3252. [CrossRef]

16. Ngo, N.T. Early predicting cooling loads for energy-efficient design in office buildings by machine learning. Energy Build. 2019, 182, 264-273. [CrossRef]

17. Ballarini, I.; De Luca, G.; Paragamyan, A.; Pellegrino, A.; Corrado, V. Transformation of an office building into a nearly zero energy building (nZEB): Implications for thermal and visual comfort and energy performance. Energies 2019, 12, 895. [CrossRef]

18. Taleb, H.M. Using passive cooling strategies to improve thermal performance and reduce energy consumption of residential buildings in U.A.E. buildings. Front. Archit. Res. 2014, 3, 154-165. [CrossRef] 
19. Nematchoua, M.K.; Tchinda, R.; Orosa, J.A.; Andreasi, W.A. Effect of wall construction materials over indoor air quality in humid and hot climate. J. Build. Eng. 2015, 3, 16-23. [CrossRef]

20. Khan, H.S.; Asif, M.; Mohammed, M.A. Case study of a nearly zero energy building in Italian climatic conditions. Infrastructures 2017, 2, 19. [CrossRef]

21. Orosa, J.A.; Oliveira, A.C. Passive Methods as a Solution for Improving Indoor Environments; Springer-Verlag London Limited: London, UK, 2012.

22. Ahmad, T.; Chen, H.; Guo, Y.; Wang, J. A comprehensive overview on the data driven and large scale based approaches for forecasting of building energy demand: A review. Energy Build. 2018, 165, 301-320. [CrossRef]

23. Gemini Data Loggers 2016. Available online: http://www.geminidataloggers.com (accessed on 24 March 2019).

24. Hameury, S.; Lundstrom, T. Contribution of indoor exposed massive wood to a good indoor climate: In situ measurement campaign. Energy Build. 2004, 36, 281-292. [CrossRef]

25. Karkalos, N.E.; Efkolidis, N.; Kyratsis, P.; Markopoulos, A.P. A comparative study between regression and neural networks for modeling Al6082-T6 alloy drilling. Machines 2019, 7, 13. [CrossRef]

26. Neto, F.C.; Geronimo, T.M.; Cruz, C.E.D.; Aguiar, P.R.; Bianchi, E.E.C. Neural models for predicting hole diameters in drilling processes. Procedia CIRP 2013, 12, 49-54. [CrossRef]

27. Singh, A.K.; Panda, S.S.; Pal, S.K.; Chakraborty, D. Predicting drill wear using an artificial neural network. Int. J. Adv. Manuf. Technol. 2006, 28, 456-462. [CrossRef]

28. Nalbant, M.; Gokkaya, H.; Toktas, I. Comparison of regression and artificial neural network models for surface roughness prediction with the cutting parameters in CNC turning. Model. Simul. Eng. 2007, 2007, 92717. [CrossRef]

29. MatlabWorks 2016. Create, Train, and Simulate Neural Networks. Available online: https://www.mathworks. com/products/neural-network.html (accessed on 26 April 2019).

30. Oh, J.; Hong, T.; Kim, H.; An, J.; Jeong, K.; Koo, C. Advanced strategies for net-zero energy building: Focused on the early phase and usage phase of a building's life cycle. Sustainability 2017, 9, 2272. [CrossRef]

31. Lu, S.; Wang, R.; Zheng, S. Passive optimization design based on particle swarm optimization in rural buildings of the hot summer and warm winter zone of China. Sustainability 2017, 9, 2288. [CrossRef]

32. Prabal-Talukdar, U.; Das, A.; Alagirusamy, R. Effect of structural parameters on thermal protective performance and comfort characteristic of fabrics. J. Text. Inst. 2017, 108, 1430-1441. [CrossRef]

33. Trník, A.; Vozár, L. Modeling of heat capacity peaks and enthalpy jumps of phase-change materials used for thermal energy storage. Int. J. Heat Mass Transf. 2017, 107, 123-132. [CrossRef] 